\title{
Food Hygiene Knowledge, Attitudes and Practices of the Food Handlers in the Military Hospitals*
}

\author{
Labib Sharif $^{1 \#}$, Mohammad M. Obaidat ${ }^{1}$, Mohammad-Raed Al-Dalalah ${ }^{2}$ \\ ${ }^{1}$ Department of Veterinary Pathology and Public Health, Faculty of Veterinary Medicine, Jordan University of Science and Tech- \\ nology, Irbid, Jordan; ${ }^{2}$ Department of Food Safety, Jordanian Army, Amman, Jordan. \\ Email: "labibsharif@yahoo.com
}

Received January $16^{\text {th }}, 2013$; revised February $16^{\text {th }}, 2013$; accepted February $24^{\text {th }}, 2013$

\begin{abstract}
Improper practices and lack of knowledge by food handlers are contributing factors for the spread of foodborne outbreaks. This study aimed to explore the knowledge, attitude and practice of food handlers in military hospitals in Jordan. A Self completed questionnaire was answered by 200 employees; 150 military employees and 50 civilian employees in 7 Jordanian military hospitals selected randomly one from the capital Amman and two from the three provinces. The results showed that the means of the percentage scores for the knowledge, attitude, practice, were 84.82, 88.88, 89.43, respectively and the overall knowledge, attitude, practice (KAP) mean percentage score was 87.88 . A significant difference $(P<0.05)$ in these values was observed between the military and civilian employee. The mean percentage scores for knowledge, attitude and practice were 88.5, 93.2, and 91.4, respectively for military employee compared to those for civilian employee of 73.7, 75.8, and 83.5, respectively. A significant difference for the overall (KAP) mean percentage score was also observed between gender, education and specific occupation of the food handler. Female KAP percentage mean score was 90.0 and that for males was 86.6; The college or university educations employee had a mean score of 91.6 while the elementary school education employee had a mean score of 79.7; The nutritionists and cooks had statistically similar means of 91.6 but these occupations significantly differ from the waiters 84.4 and cleaners 80.2.
\end{abstract}

Keywords: Knowledge; Attitude; Practice; Food Handlers; Jordan

\section{Introduction}

Food handlers play a major role in transmitting pathogens passively from contaminated sources such as transmitting pathogens from raw meat to a ready to eat food. Food handlers may also carry some human specific foodborne pathogens such as Hepatitis A, noroviruses, typhoidal Salmonella, Staphylococcus aureus and Shigella sp in their hands, cuts or sores, mouth, skin and hair. Food handlers may also shed foodborne pathogens, such as E. coli O157:H7 and non-typhoidal Salmonella during the infectiousness period or less important during recovery period of a gastrointestinal sickness [1].

Todd et al. [2] formed a workgroup and analyzed 816 foodborne outbreaks where food workers have been implicated in the spread of foodborne diseases. They have published a series of peer-reviewed papers in the journal of food protection from 2007 to 2011. In the third publication, they categorized the factor contributing to outbreaks into food worker error factors, bacterial prolifera-

\footnotetext{
*Authors declare no conflict of interest.

${ }^{\#}$ Corresponding author.
}

tion factors, and important survival factors for pathogens. The most frequently reported food worker errors were handling of food by a person either actively infected by or carrying a pathogen, bare-hand contact with food, failure to properly wash hands when necessary, insufficient cleaning of processing or preparation equipment or kitchen tools. Such unhygienic practice would cause contamination of the food and cross-contamination of ready-to-eat (RTE) foods [1,2].

Several studies were conducted to evaluate the food safety knowledge, attitude and practice (KAP) of food handlers in restaurants and food establishments [3-6]. Other target populations for food safety KAP studies were university students $[7,8]$ and hospitals' staff or food handlers $[9,10]$. In this study, the overall knowledge, attitude and practice (KAP) scores of the food handlers in military hospitals were explored for the first time in Jordan. These KAP scores were compared between military and civilian food handlers. The identified specific unhygienic practice, negative attitude and lack of knowledge that increase the risk of food poisoning will be addressed in food safety training programs for food handlers. 


\section{Materials and Methods}

\subsection{Target Population, Setting, and Instrument for Getting the Information}

Food handlers in Jordanian military hospitals are the target population for this study. A modified Sharif and AlMalki (2010) questionnaire for Knowledge, attitude and practice of the food handlers was used [7]. The questionnaire consisted of fifty questions divided into three parts. Part one included 15 questions about the knowledge, part two included 15 questions about the attitude and part three included 20 questions about the practice. All questions about knowledge and attitude were scored on a five-point scale (0 to 4) with options of strongly agrees, agree, not sure, disagree or strongly disagree. But, the questions about practice were scored on a five-point scale (0 to 4 ) with options of always, most of the times, sometimes, rarely or never. The direction of the scale was (4 to 0 ) and reversed to (0 to 4 ) for some questions to check the validity of the responses. For dichotomous classification the scores less than 3 were categorized as a negative response, (Answering wrong) while the scores 3 and 4 were categorized as a positive response (Answering right). The questionnaire stated clearly to the participants that the information will be used only for scientific purposes and the participants signed a consent form.

\subsection{Sampling Technique}

A random cluster sampling was used. The military hospitals were stratified into 4 areas; namely, Amman, Northern, Middle and Southern provinces. Seven hospitals, one from Amman and two from each of the three provinces, were selected randomly. All food handlers in the selected hospitals were asked to complete the questionnaire by themselves (Self completed questionnaire).

\subsection{Data Analysis}

A variable file was created on SPSS version 20. The 5 point score for the variables were ranged from 0 to 4 . The mean score of each question was transformed into percentage score (dividing that score by 4 , the highest possible score then multiply by $100 \%$ ) to simplify the presentation and interpretation of the results. Descriptive statistics were performed for each question of the knowledge, attitude, practice and the overall KAP mean percentage score. One way ANOVA test was used to compare the mean score of knowledge, attitude, and practice among the different four educational levels, professions of the food handlers (cook, food server, and nutritionist). Turkey's and LSD tests were used after ANOVA to identify significant difference between the two populations. The mean score of knowledge, attitude, and practice were compared by $t$-test according to gender (Female vs Male), professional experience (High vs Low) and military vs civilian employee. The responses were also reclassified into two categorical responses yes and no (correct and incorrect response). The rate of correct responses for each question was then described.

\section{Results and Discussion}

\subsection{Demographic Characteristics}

A total of 200 food handlers in 7 military hospitals in Jordan were included in this study; 150 military and 50 civilian employees. The gender of surveyed food handlers was 125 male and 75 female with a ratio of male to female 1.66:1. The occupations of the participants were 68 waiters, 61 cooks, 51 nutritionists, and 20 cleaners. The participants worked in different geographical location in Jordan, specifically 63 in Amman, 49 in Northern Jordan, 48 in Southern Jordan, and 40 in Middle Jordan. The mean age of participants was $29.40 \pm 5.60$, and ages ranged between 18 to 50 years. The mean length of employment was $4.08 \pm 2.37$ and experience ranged from 1 to 15 years (Table 1).

Table 1. Demographic characteristics of food handlers in military hospitals in Jordan.

\begin{tabular}{|c|c|c|c|c|}
\hline Characteristic & $n$ & $\%$ & Mean \pm SD & Range \\
\hline \multicolumn{5}{|l|}{ Employee Category } \\
\hline Military & 150 & 75 & NA & NA \\
\hline Civilian & 50 & 25 & NA & NA \\
\hline Education & & & NA & NA \\
\hline University & 28 & 14 & NA & NA \\
\hline Community college & 56 & 28 & NA & NA \\
\hline High School & 104 & 52 & NA & NA \\
\hline Elementary & 12 & 6 & NA & NA \\
\hline Occupation & & & NA & NA \\
\hline Nutritionist & 51 & 25.5 & NA & NA \\
\hline Cleaner & 20 & 10 & NA & NA \\
\hline Waiter & 68 & 34 & NA & NA \\
\hline Cooker & 61 & 30.5 & NA & NA \\
\hline Province & & & NA & NA \\
\hline Amman & 63 & 31.5 & NA & NA \\
\hline South & 48 & 24 & NA & NA \\
\hline Middle & 40 & 20 & NA & NA \\
\hline North & 49 & 24.5 & NA & NA \\
\hline Gender & & & NA & NA \\
\hline Male & 125 & 62.5 & NA & NA \\
\hline Female & 75 & 37.5 & NA & NA \\
\hline Age & NA & NA & $29.4 \pm 5.6$ & $18-50$ \\
\hline Years of Experience & NA & NA & $4.08 \pm 2.37$ & $1-15$ \\
\hline
\end{tabular}

NA: Not Applicable. 


\subsection{Overall Knowledge, Attitude and Practice}

The food handlers in the military hospitals expressed high level of knowledge, positive attitude and good practice in food safety. The means of the percentage scores for the knowledge, attitude, practice, and overall KAP were $84.82 \% \pm 11.71 \%, 88.88 \% \pm 12.67 \%$, $89.43 \% \pm$ $9.10 \%$, and $87.88 \% \pm 9.61 \%$ respectively.

\subsection{Food Handlers' Knowledge}

In general, the food handlers' knowledge was high with a mean percentage score of $84.83 \% \pm 11.71 \%$. They demonstrated excellent knowledge in the categories of high risk foods, foodborne diseases, food storage temperatures, and sources of food contamination. But, they have a lack of knowledge about the proper method of thawing frozen food, where $90 \%$ thought that the correct method for thawing frozen meat and broiler is to keep them overnight at room temperature (Table 2). A study found that the participants had good knowledge on personal hygiene and definition of foodborne diseases with mean score of 93.85\% and $73.85 \%$, respectively [11]. On the contrary, their knowledge on food storage and preparation temperatures was poor with only 28\% [11]. Another study [12] on 124 food handlers in 32 school canteens in Portugal, found that the food handlers displayed reasonable level of knowledge in personal hygiene and cross contamination, but fared worse in other areas. The level of knowledge, as in our study, was influenced by age, motivation and training. On the other hand, other studies showed that food handlers have low level of knowledge about food hygiene issues. In a study that was performed in small and micro enterprises, to assess food handlers' knowledge on food hygiene ( $n=159)$, in South Africa, the average percentage of correct answers was 46.0\% [13] and in another study in Ankara, Turkey, the mean food safety knowledge score of food handlers $(n=764)$ was $43.4 \% \pm 16.3 \%$ [14].

In our study, the food handlers correctly answered that foodborne pathogens cannot be observed by the naked eye. But, other studies showed that between $52.5 \%$ and $64.4 \%$ wrongly believed that they can tell if food was contaminated with food poisoning bacteria by visual, olfactory or taste checks [15-18]. Our study showed that the food handlers have a good knowledge of temperature control knowledge and they practiced such knowledge. But other studies carried out in Turkey, Portugal, United Kingdom, Slovenia and Italy demonstrated that food handlers lack the knowledge regarding temperature control as a measure to reduce the risk of food poisoning [3, $9,13,15,16,18]$. Temperature control of ready to eat food and cooked food are crucial steps in catering industry to prevent the growth of foodborne pathogen to an infectious level. Specifically, improper holding temperature and slow cooling of hot foods, promote growth of $B$. cereus and $C l$. perfringens to disease-causing levels [19]. Moreover, improper storage of ready to eat food facilitates the growth of Listeria monocytogenes to an infectious level.

\subsection{Food Handlers' Attitude}

The response of food handlers to the attitude questionnaire on food poisoning is presented in Table 3 . In general, the food handlers' attitude toward safe food handling was high with mean percentage score of $88.9 \% \pm$ $12.7 \%$.

Table 2. Response of food handlers in military hospitals to knowledge questions on food poisoning in Jordan.

\begin{tabular}{|c|c|c|}
\hline Question & Positive Answer (\%) & Negative Answer (\%) \\
\hline 1) Food poisoning is caused by pathogenic microbes & $(93.5)$ & $(6.5)$ \\
\hline 2) Eating raw or half - cooked meat is highly risky for food poisoning & $(95.5)$ & $(4.0)$ \\
\hline 3) Eating raw unwashed vegetables is highly risky for food poisoning & $(96)$ & $(4.0)$ \\
\hline $\begin{array}{l}\text { 4) Food handlers with unhygienic practice could be the source for food contamination } \\
\text { with food poisoning pathogens }\end{array}$ & $(93.5)$ & $(6.5)$ \\
\hline $\begin{array}{l}\text { 5) Eating covered leftover cooked food, kept at room temperature for more than } 6 \text { hours, } \\
\text { is at high risk to cause food poisoning }\end{array}$ & $(91.5)$ & $(8.5)$ \\
\hline 6) Keeping food at refrigerator temperature helps to prevent food poisoning & $(98.5)$ & $(1.5)$ \\
\hline $\begin{array}{l}\text { 7) Contacting ready to eat food with bare hands cause food contamination with food } \\
\text { poisoning pathogens }\end{array}$ & $(93)$ & $(7.0)$ \\
\hline $\begin{array}{l}\text { 8) The correct method for thawing frozen meat or broiler is to keep them overnight at } \\
\text { room temperature }\end{array}$ & $(10)$ & $(90)$ \\
\hline 9) Food poisoning could cause severe diseases that end in hospitalization and sometimes death & $(92.5)$ & $(7.5)$ \\
\hline 10) Apparently healthy food handlers might carry foodborne pathogens & $(79)$ & $(21)$ \\
\hline 12) Harmful bacteria multiply quickly at room temperature & $(86)$ & $(14)$ \\
\hline 13) Foodborne pathogens can be seen by the eye & (88) & $(12)$ \\
\hline 14) Vegetables should be placed on higher shelf in refrigerator than meat and poultry & $(85.5)$ & $(14.5)$ \\
\hline 15) Cooked food leftover should be re-heated thoroughly & $(96)$ & $(4.0)$ \\
\hline
\end{tabular}


Table 3. Response of food handlers in military hospitals to attitude questions on food poisoning in Jordan.

\begin{tabular}{|c|c|c|}
\hline Question & Positive Answer (\%) & Negative Answer (\%) \\
\hline 16) Safe food handling is an important part of my job responsibilities & $(93.5)$ & $(6.5)$ \\
\hline 17) Learning more about food safety through training courses is important to me & $(95.5)$ & $(4.0)$ \\
\hline 18) It is important to check the temperature of the refrigerator to prevent food poisoning & $(96)$ & $(4.0)$ \\
\hline 19) Raw foods should be kept separately from cooked foods & $(93.5)$ & (6.5) \\
\hline 20) Food handlers can be a source of foodborne outbreaks & $(91.5)$ & (8.5) \\
\hline 21) Wiping vegetables or fruits make them safe to be eaten & $(98.5)$ & (1.5) \\
\hline $\begin{array}{l}\text { 22) Thorough washing of vegetables and fruits in tap water is necessary to } \\
\text { prevent food poisoning }\end{array}$ & (93) & $(7.0)$ \\
\hline 23) Beards could contaminate food with foodborne pathogens & (10) & $(90)$ \\
\hline 24) Long fingernails could contaminate food with foodborne pathogens & $(92.5)$ & $(7.5)$ \\
\hline 25) Raw vegetables and meat should not be cut by the same knife & (79) & $(21)$ \\
\hline 26) Raw vegetables and meat should not be cut on the same cutting board & $(96)$ & $(4.0)$ \\
\hline 27) Food handlers should be medically examined every six months & $(86)$ & (14) \\
\hline $\begin{array}{l}\text { 28) Wiping off the cutting board with a clean paper towel between food items } \\
\text { (raw meat and bread) is enough to prevent spreading of foodborne pathogens. }\end{array}$ & (88) & (12) \\
\hline $\begin{array}{l}\text { 29) Before handling food, rinsing your hand with cold water is enough to get rid } \\
\text { of the bacteria on your hands }\end{array}$ & $(85.5)$ & $(14.5)$ \\
\hline 30) Foodborne outbreaks are natural life event & $(96)$ & $(4.0)$ \\
\hline
\end{tabular}

\subsection{Food Handlers’' Practice}

The response of food handlers to the practice questions on food safety is presented in Table 4. In general, the food handlers practiced good hygiene level with a mean percentage score of $89.4 \% \pm 9.1 \%$. They practiced critical points in general sanitary such as hand washing (94.5\% correct answers), storing cooked meat for less than $4 \mathrm{~h}$ at room temperature (89\% correct answers), cleaning food contact surfaces (98.5\% correct answers), and separating raw meat from ready-to-eat food (90\% correct answers). But, 59\% of the handlers wrongly practice drinking raw milk (Table 4). Our study showed that the handlers practiced the food hygiene and their knowledge. But, other researchers [11] found that the majority of the respondents have an average practices in all parts of the questions, despite their good knowledge. The high mean percentage score of food handlers in our study could be explained in addition to high knowledge is obeying the orders attitude of military workers. This was obvious when comparing the mean score of practice of the civilian and military food handlers in the military hospitals. The mean percentage score was significantly higher $(P<0.05)$ in military than civilian food handlers. But, other studies showed that the extensive knowledge of the correct practices for hand hygiene do not necessarily result in the appliance of these methods because of the work place barriers [20,21]. These barriers come from the work staff, including inhibitory attitudes of supervisors and colleagues, time pressures and/or lack of staff, as well as structural factors, such as facilities and accessibility to supplies. Therefore, the training of food handlers should be carried out in multidimensional ap- proach covering social, environmental and organizational factors, and with greater focus on risk perception that may lead to unsafe practices [22-24]. Our study showed that $98.5 \%$ of the respondents practiced proper cleaning and disinfecting procedure of premises, surfaces and utensils. This is crucial step in catering industry to prevent cross contamination of food. On the other sides, a study of 200 chefs in Ireland showed that $21.5 \%$ of all the respondents considered the use of disinfectants in sanitizing worktops as unimportant step [25].

\subsection{Gender}

The overall KAP mean percentage score was significantly different $(P<0.05)$ for females and males, where females mean KAP percentage score was $90.0 \pm 7.4$ and that for males was $86.6 \pm 10.5$. The mean scores for knowledge, attitude and practice were higher for females compared to those for males (Table 5).

\subsection{Education}

In the military hospital food handlers, the overall KAP scores were significantly $(P<0.05)$ affected by the levels of education, where the average scores increased with the education level. But, there was no significant difference in the education level between the military and civilian employee. The college and university educations have statistically similar means of $90.7 \pm 7.4$ and $92.1 \pm 5.0$, respectively. But, these education levels significantly differ from the elementary $(79.7 \pm 13.7)$ and secondary educations (86.2 \pm 10.4$)$. The knowledge, attitude, and practice scores were also significantly $(P<0.05)$ affected 
Table 4. Response of food handlers in military hospitals to practice questions on food poisoning in Jordan.

\begin{tabular}{|c|c|c|c|c|}
\hline \multirow{2}{*}{ Question } & \multicolumn{2}{|c|}{ Hygienic practice } & \multicolumn{2}{|c|}{ Unhygienic practice } \\
\hline & $n$ & $(\%)$ & $n$ & $(\%)$ \\
\hline 31) Do you wear gloves when you handle ready to eat food or prepare sandwiches? & 171 & $(85.5)$ & 29 & $(14.5)$ \\
\hline 32) Do you wash your hands with water and soap before preparing food? & 189 & $(94.5)$ & 11 & $(5.5)$ \\
\hline 33) Do you wash your hand with water and soap after using the bathroom? & 196 & $(98)$ & 4 & $(2.0)$ \\
\hline 34) Do you work when you have diarrhea? & 149 & $(74.5)$ & 51 & $(25.5)$ \\
\hline 35) Do you work when you have lesions on your hands? & 154 & $(77)$ & 46 & 23) \\
\hline 36) Do you allow your finger nails to grow? & 183 & $(91.5)$ & 17 & $(8.5)$ \\
\hline 37) Do you wash vegetables and fruits before slicing them? & 197 & $(98.5)$ & 3 & $(1.5)$ \\
\hline 38) Do you keep cooked meat or chicken at room temperature for more than 4 hours? & 178 & $(89)$ & 22 & $(11)$ \\
\hline 39) Do you clean food contact surfaces before and after preparing food? & 197 & $(98.5)$ & 3 & $(1.5)$ \\
\hline 40) Do you work when you have cold? & 128 & $(64)$ & 72 & $(36)$ \\
\hline 41) Do you wash fresh vegetables and fruits in tap water before eating? & 197 & $(98.5)$ & 3 & $(1.5)$ \\
\hline 42) Do you wash your hands with water and soap before eating your meal? & 191 & $(95.5)$ & 9 & $(4.5)$ \\
\hline 43) Do you wash your hands with water and soap after handling raw meat? & 198 & $(99)$ & 2 & $(1.0)$ \\
\hline 44) Do you wash your hands with water and soap after using the toilet? & 198 & $(99)$ & 2 & $(1.0)$ \\
\hline 45) Do you dry your hands after washing them with towel? & 185 & $(92.5)$ & 15 & $(7.5)$ \\
\hline 46) Do you eat half-cooked eggs (Egg yolk is soft)? & 173 & $(86.5)$ & 27 & $(13.5)$ \\
\hline 47) Do you separate raw meat from ready to eat foods? & 180 & $(90)$ & 20 & $(10)$ \\
\hline 48) Do you check the temperature of the refrigerator? & 182 & $(91)$ & 18 & $(9.0)$ \\
\hline 49) Do you drink raw (unpasteurized) milk? & 82 & $(41)$ & 118 & (59) \\
\hline 50) Do you eat half cooked meat (inside is pink)? & 188 & (94) & 12 & $(6.0)$ \\
\hline
\end{tabular}

Table 5. Mean percentage score for knowledge, attitude, practice and KAP according to gender of the food handlers in military hospitals in Jordan.

\begin{tabular}{ccccc}
\hline Character & Gender & $\boldsymbol{n}$ & Mean & SD \\
\hline \multirow{2}{*}{ Knowledge percentage } & Male & 125 & 83.60 & 12.58 \\
& Female & 75 & $86.87^{*}$ & 9.87 \\
Attitude percentage & Male & 125 & 87.31 & 13.62 \\
& Female & 75 & $91.49^{*}$ & 10.50 \\
Practice percentage & Male & 125 & 88.31 & 10.28 \\
& Female & 75 & $91.28^{*}$ & 6.35 \\
KAP percentage & Male & 125 & 86.60 & 10.53 \\
& Female & 75 & $90.02^{*}$ & 7.44 \\
\hline
\end{tabular}

*Significant difference between the means $(P<0.05)$ by t-test.

by the levels of education, where the average scores increased with the education level. Our findings corroborate with other studies. For example, a study carried out in Ankara (Turkey) to determine employees' $(n=400)$ perception of hygiene in the catering industry [14] found a significant difference among different levels of education, where participants with university education had better perception.

\subsection{Occupation}

In the military hospital food handlers, the overall KAP score was significantly $(P<0.05)$ affected by type of work; where the cooks and nutritionist KAP scores were statistically similar, but waiters and cleaners were grouped in another group. The nutritionists and cooks had statistically similar means of $91.6 \pm 6.0$ and $91.1 \pm 7.2$, respectively. But, these occupations significantly differ from the waiters (84.4 \pm 11.4$)$ and housekeepers (80.2 \pm 9.1). The KAP scores for waiters and cleaners were statistically similar. The knowledge, attitude, and practice score were also significantly $(P<0.05)$ affected by the occupation, where the average scores for nutritionists and cookers were statistically similar, but both differ from those for waiters and housekeepers.

\subsection{Professional Experience}

In the full questionnaire scores, no statistically significant difference was found between participants of different experience levels. Despite the average score differences between the categories (the most experienced participants with the higher score and the less experienced with the lower score). But, in the group of questions in which less than $50 \%$ of correspondents responded correctly, there is a statistically significant difference $(P$ $<0.05$ ) between results obtained by participants with different professional experience. Participants with more than five years of experience have higher scores than those with work experience of between one and three years $(P<0.05)$. 


\subsection{Military vs Civilian Employee}

The overall KAP scores were significantly different $(P<$ 0.05 ) for military and civilian employee; where military employees mean KAP score was $91.1 \pm 8.0$ and that for civilian employees was $78.3 \pm 7.5$. The mean scores for knowledge, attitude and practice were higher for military employee of $88.5 \pm 9.8,93.2 \pm 10.2$, and $91.4 \pm 8.0$, respectively compared to those for civilian employee of $73.7 \pm 10.0,75.8 \pm 10.1$, and $83.5 \pm 9.6$, respectively. There was no significant difference $(P>0.05)$ between the two groups in terms of education, or sex. The rates of college or university education in military and civilian employees were $43.3 \%$ and $36 \%$ respectively and the rates of female in military and civilian employees were $38.7 \%$ and $34 \%$ respectively therefore this difference in KAP scores might be attributed to the "obeying the order" attitude of the military employee and more food hygiene training of the military employee. This agrees with other study which confirmed that educational intervention improves KAP of food handlers, based on that study which involved 370 Iranian food handlers [26]. Another study [27] also found that the level of knowledge was higher in FOODSAFE trained food handlers compared to untrained handlers. But, they confirmed that training and recertification is needed since food safety knowledge decreased over 25 years' period post-certification.

\section{Conclusion}

This investigation provides valuable information about the level of knowledge, attitude, and practice in food safety of food handlers in military hospitals in Jordan. An important result from this study showed that the overall KAP scores were significantly higher $(P<0.05)$ in military (91.1) than in civilian employees (78.3). Educating, training and promoting positive attitude of food handlers would improve the status of food hygiene knowledge, attitudes and practices.

\section{Acknowledgements}

This work was supported by the Deanship of Research at Jordan University of Science and Technology; research number 25/2012. We thank the cooperation of the military Jordanian hospitals in conducting this study.

\section{REFERENCES}

[1] M. R. Adams and M. O. Moss, "Food Microbiology,” 3rd Edition, The Royal Society of Chemistry, Cambridge, 2008.

[2] E. C. Todd, J. D. Greig, C. A. Bartleson and B. S. Michaels, "Outbreaks Where Food Workers Have Been Implicated in the Spread of Foodborne Disease, Part 3.
Factors Contributing to Outbreaks and Description of Outbreak Categories,” Journal of Food Protection, Vol. 70, No. 9, 2007, pp. 2199-2217.

[3] M. Bas, A. Ersun and G. Kıvanç, "The Evaluation of Food Hygiene Knowledge, Attitudes, and Practices of Food Handlers' in Food Businesses in Turkey," Food Control, Vol. 17, No. 4, 2006, pp. 317-322. doi:10.1016/j.foodcont.2004.11.006

[4] A. D. Howells, K. R. Roberts, C. W. Shanklin, V. K. Pilling, L. A. Brannon and B. B. Barrett, "Restaurant Employees' Perceptions of Barriers to Three Food Safety Practices," Journal of the American Dietetic Association, Vol. 108, No. 8, 2008, pp. 1345-1349.

doi:10.1016/j.jada.2008.05.010

[5] S. S. Lilian, C. C. Rogeria, S. C. Ellayne, S. C. Joelza and L. N. Itaciara, "Knowledge, Attitudes and Practices in Food Safety and the Presence of Coagulase-Positive Staphylococci on Hands of Food Handlers in the Schools of Camaçari, Brazil,” Food Control, Vol. 27, No. 1, 2012, pp. 206-213. doi:10.1016/j.foodcont.2012.03.016

[6] A. S. Pragle, A. K. Harding and J. C. Mack, "Food Workers' Perspectives on Hand Washing Behaviors and Barriers in the Restaurant Environment," Journal of Environmental Health, Vol. 69, No. 10, 2007, pp. 27-32.

[7] L. Sharif and T. Al-Malki, "Knowledge, Attitude and Practice of Taif University Students on Food Poisoning," Food Control, Vol. 21, No. 1, 2010, pp. 55-60. doi:10.1016/j.foodcont.2009.03.015

[8] N. Unklesbay, J. Sneed and R. Toma, "College Students' Attitudes, Practices, and Knowledge of Food Safety," Journal of Food Protection, Vol. 61, No. 9, 1998, pp. 1175-1180.

[9] C. Buccheri, A. Casuccio, S. Giammanco, M. Giammanco, M. La Guardia and C. Mammina, "Food Safety in Hospital: Knowledge, Attitudes and Practices of Nursing Staff of Two Hospitals in Sicily, Italy,” BMC Health Service Research, Vol. 7, No. 45, 2007, pp. 1-11. doi:10.1186/1472-6963-7-45

[10] H. El Derea, E. Salem, M. Fawzi and M. A. Azeem, "Safety of Patient Meals in 2 Hospitals in Alexandria, Egypt before and after Training of Food Handlers," East Mediterranean Health Journal, Vol. 14, No. 4, 2008, pp. 941-952.

[11] S. O. Nee and A. S. Norrakiah, "Assessment of Knowledge, Attitudes and Practices (KAP) among Food Handlers at Residential Colleges and Canteen Regarding Food Safety,” Sains Malaysiana, Vol. 40, No. 4, 2011, pp. 403-410.

[12] M. J. Santos, J. R Nogueira, L. Patarata and O. Mayan, "Knowledge Levels of Food Handlers in Portuguese School Canteens and Their Self-Reported Behavior towards Food Safety," International Journal of Environmental Health Research, Vol. 18, No. 6, 2008, pp. 387401. doi:10.1080/09603120802100212

[13] M. Marais, N. Conradie and D. Labadarios, "Small and Micro Enterprises-Aspects of Knowledge, Attitudes and Practices of Managers' Hospital, Western Cape," South African Journal Clinical Nutrition, Vol. 20, No. 2, 2007, pp. 50-61. 
[14] F. P. Çakiroglu and A. Uçar, “Employees’ Perception of Hygiene in the Catering Industry in Ankara (Turkey)," Food Control, Vol. 19, No. 1, 2008, pp. 9-15. doi:10.1016/i.foodcont.2007.01.001

[15] E. Gomes-Neves, A. C. Araújo, E. Ramos and C. S. Cardoso, "Food Handling: Comparative Analysis of General Knowledge and Practice in Three Relevant Groups in Portugal,” Food Control, Vol. 18, No. 6, 2007, pp. 707712. doi:10.1016/j.foodcont.2006.03.005

[16] M. Jevšnik, V. Hlebec and P. Raspor, "Food Safety Knowledge and 553 Practices among Food Handlers in Slovenia,” Food Control, Vol. 19, No. 12, 2008, pp. 1107-1111. doi:10.1016/j.foodcont.2007.11.010

[17] R. B. Martins, T. Hogg and J. G. Otero, "Food Handlers' Knowledge on Food Hygiene: The Case of a Catering Company in Portugal," Food Control, Vol. 23, No. 1, 2012, pp. 184-190. doi:10.1016/j.foodcont.2011.07.008

[18] E. Walker, C. Pritchard and S. Forsythe, "Food Handlers' Hygiene Knowledge in Small Food Businesses," Food Control, Vol. 14, No. 5, 2003, pp. 339-343. doi:10.1016/S0956-7135(02)00101-9

[19] B. J. McCabe-Sellers and S. E. Beattie, "Food Safety: Emerging Trends in Food Borne Illness Surveillance and Prevention,” Journal of the American Dietetic Association, Vol. 104, No. 11, 2004, pp. 1708-1717. doi:10.1016/j.jada.2004.08.028

[20] D. A. Clayton, C. J. Griffith, P. Price and A. C. Peters, "Food Handlers' Beliefs and Self-Reported Practices," International Journal of Environmental Health Research, Vol. 12, No. 1, 2002, pp. 25-29. doi:10.1080/09603120120110031

[21] L. Green, C. Selman, V. Radke, D. Ripley, J. Mack, D. Reimann, T. Stigger, M. Motsinger and L. Bushnell,
"Food Worker Hand Washing Practices: An Observational Study,” Journal of Food Protection, Vol. 69, No. 10, 2006, pp. 2417-2423.

[22] P. Coleman, C. Griffith and D. Botterill, "Welsh Caterers: An Exploratory Study of Attitudes towards Safe Food Handling in the Hospitality Industry," International Journal of Hospitality Management, Vol. 19, No. 2, 2000, pp. 145-157. doi:10.1016/S0278-4319(00)00010-4

[23] J. E. Ehiri, G. P. Morris and J. McEwen, "Evaluation of a food hygiene training course in Scotland," Food Control, Vol. 8, No. 3, 1997, pp. 137-147. doi:10.1016/S0956-7135(97)00005-4

[24] M. D. Rennie, "Health Education Models and Food Hygiene Education,” Perspectives in Public Health, Vol. 115, No. 2, 1995, pp. 75-79. doi:10.1177/146642409511500203

[25] D. J. Bolton, A. Meally, I. S. Blair, D. A. McDowell and C. Cowan, "Food Safety Knowledge of Head Chefs and Catering Managers in Ireland," Food Control, Vol. 19, No. 3, 2008, pp. 291-300. doi:10.1016/j.foodcont.2007.04.006

[26] M. Pirsaheb, A. Almasi and M. Rezaee, "The Special Health Education Course Effects on Knowledge, Attitude and Practice of Preparation, Distribution and Sale Centers Food Staff in Kermanshah," Iranian Journal of Health and Environment, Vol. 3, No. 3, 2010, pp. 299-308.

[27] L. McIntyre, L. Vallaster, L. Wilcott, S. B. Henderson and T. Kosatsky, "Evaluation of Food Safety Knowledge, Attitudes and Self-Reported Hand Washing Practices in FOODSAFE Trained and Untrained Food Handlers in British Columbia, Canada,” Food Control, Vol. 30, No. 1, 2012, pp. 150-156. doi:10.1016/j.foodcont.2012.06.034 